\title{
Production of Sustainable Hydrogen and Carbon for the Metallurgical Industry ${ }^{+}$
}

\author{
Roar Jensen *, Casper van der Eijk *D and Aud N. Wærnes *
}

SINTEF Industry, Department for Metal-Production and Processing, Alfred Getz'vei 2b, 7034 Trondheim, Norway

* Correspondence: roar.jensen@sintef.no (R.J.); casper.eijk@sintef.no (C.v.d.E.); Aud.N.Warnes@sintef.no (A.N.W.)

+ Presented at the International Conference on Raw Materials and Circular Economy, Athens, Greece, 5-9 September 2021.

\begin{abstract}
Hydrogen will presumably become an important substitute for carbon as a reductant in the metallurgical industry for processes such as steel production. However, the challenge to supply enough $\mathrm{CO}_{2}$-free hydrogen for metallurgical processes has not been resolved yet. This paper reviews different production technologies for hydrogen and their advantages and drawbacks. Additionally, it will highlight the development of plasma technology to produce hydrogen and carbon black which has been taking place at SINTEF during the last 30 years.
\end{abstract}

Keywords: hydrogen; plasma; carbon black

check for updates

Citation: Jensen, R.; van der Eijk, C.; Wærnes, A.N. Production of Sustainable Hydrogen and Carbon for the Metallurgical Industry. Mater. Proc. 2021, 5, 67. https://doi.org/ 10.3390/materproc2021005067

Academic Editor: Anthimos Xenidis

Published: 10 December 2021

Publisher's Note: MDPI stays neutral with regard to jurisdictional claims in published maps and institutional affiliations.

Copyright: (c) 2021 by the authors. Licensee MDPI, Basel, Switzerland. This article is an open access article distributed under the terms and conditions of the Creative Commons Attribution (CC BY) license (https:// creativecommons.org/licenses/by/ $4.0 /)$.

\section{Introduction}

The most common method for producing hydrogen today is by steam reforming hydrocarbons called grey hydrogen. This results in high $\mathrm{CO}_{2}$ emissions. However, natural gas can also be converted to hydrogen without the carbon emissions, via another spectrum of the hydrogen palette. These include "blue hydrogen" - steam-methane reforming with carbon capture and storage-or another technique, methane pyrolysis, that has earned the moniker of "turquoise" for merging blue and green. When this latter technique is run with biomethane produced by the anaerobic digestion of organic waste, then these hydrogen and carbon produced can be considered $\mathrm{CO}_{2}$-free as long as the electric energy input from low-carbon energy sources is used. Methods to produce turquoise hydrogen include thermal decomposition by thermal plasma, catalytic thermal decomposition, the splitting of methane in molten metal/salt baths and methane splitting in cold plasma.

The development of a method to crack hydrocarbons into carbon black and hydrogen with use of thermal plasma technology was started in 1989 by the Norwegian company Kvaerner together with SINTEF. A SINTEF-invented graphite plasma torch was used to supply electric heat to the process. An extensive experimental program was carried out including tests in a $150 \mathrm{~kW}$ plasma reactor at the SINTEF laboratory in Trondheim, Norway [1]. In 1992, a 3 MW pilot scale reactor was installed at ScanArc in Hofors, Sweden.

Kvaerner built a commercial scale plant in Montreal, Canada that started operations in 1998. The plant was closed down in 2002 for reasons including financial issues as well as problems related to difficulties in producing the right carbon black qualities for the market (Myklebust, 2020). The US-based company Monolith Materials bought the rights in 2013 and further developed the Kvaerner/SINTEF technology. Monolith has now constructed a plant in Hallam, Nebraska that is in the late stages of commissioning. SINTEF still has the rights to utilize the technology for metallurgical purposes.

German chemist giant BASF and Hazer Group Limited in Australia are leading contenders in catalytic thermal decomposition. BASF uses a vertical reactor with a moving carbon bed heated to above $800{ }^{\circ} \mathrm{C}$ by electric induction where natural gas is introduced from the bottom of the reactor. The hydrogen product comes out at the top of the reactor, and particulate carbon product is collected at the bottom of the reactor. The technical 
feasibility was examined at laboratory scale, and tests in a 15-meter-high test facility in Ludwigshafen have been started. The various approaches to the use and storage of pyrolysis carbon are being investigated. There will not be any prospects for industrialization before $2025[2,3]$.

Hazer Group uses a fluidized bed tube reactor externally heated to $900{ }^{\circ} \mathrm{C}$ in which fluidized iron ore particles are used as catalysts, and graphite product is formed on the surface of the particles. Natural gas is introduced from the bottom of the reactor. A mixture of hydrogen and methane with fine graphite particles of 80-95\% purity leaves from the top of the reactor. Graphite is filtered from the off gas and hydrogen is separated from the rest of the gas in a separate step. The Hazer group sees potential in the use of the highly crystalline graphite product in lithium-ion batteries in the possible commercial market. The Hazer Group is operating a pilot plant situated in Kwinana, Western Australia and is planning to build a commercial demonstration plant $[2,4]$.

Thermal catalytic splitting of methane at temperatures around $1000{ }^{\circ} \mathrm{C}$ in molten metal and salt baths is a technology that has been investigated for a long time. Today, nickelbismuth is the preferred alloy, as it can convert 90 to $95 \%$ of methane to hydrogen and solid carbon. The challenges of this technology include the separation of carbon product from the metal bath and the qualities of hydrogen and carbon products. A coalition of European companies including the Dutch research organization TNO is working on splitting methane in molten metal baths using a micro-bubbling technic, reducing reaction time and reactor volume and a molten salts concept for the effective separation of the carbon from the bath. TNO expects that the technology will be commercially available around 2030-2035 [2].

Methane splitting in cold plasma has been studied at the Tomsk Polytechnic Institute in Russia. The technology may be highly efficient, but it is still at the laboratory stage. Atlantic Hydrogen in New Brunswick (Canada) was in the process of developing cold plasma technology for the pyrolysis of natural gas from 2010 to 2015 but filed for bankruptcy in 2015 [2].

\section{Hydrogen Production Technologies}

Hydrogen produced by different technologies has been given color monikers indicating environmental impact. Brown, gray, blue, green and turquoise are among the colors used.

\subsection{Brown Hydrogen}

The gasification of coal is a technology that can produce power, liquid fuels, chemicals and hydrogen. Hydrogen produced from coal or lignite is called brown hydrogen. For the production of hydrogen, coal first reacts with oxygen and steam under high pressures and temperatures to form synthesis gas, which consists of carbon monoxide, hydrogen, carbon dioxide and some impurities that are later removed. In the next step the carbon monoxide reacts with steam, using the water-gas shift reaction. The reaction produces additional hydrogen and carbon dioxide. Hydrogen is removed by a separation system. The high carbon content of the raw materials results in high $\mathrm{CO}_{2}$ emissions [5].

Coal gasification reaction (unbalanced):

$$
\mathrm{CH}_{0.8}+\mathrm{O}_{2}+\mathrm{H}_{2} \mathrm{O} \rightarrow \mathrm{CO}+\mathrm{CO}_{2}+\mathrm{H}_{2}+\text { other species }
$$

Water-gas shift reaction:

$$
\mathrm{CO}+\mathrm{H}_{2} \mathrm{O} \rightarrow \mathrm{CO}_{2}+\mathrm{H}_{2} \text { (+ small amount of heat) }
$$

\subsection{Gray Hydrogen}

Hydrogen produced from methane sources such as natural gas is called gray hydrogen. Gray hydrogen is mainly produced by steam methane reforming (SMR) and the partial oxidation of methane. Hydrogen produced by these processes has lower $\mathrm{CO}_{2}$ emissions than brown hydrogen produced from coal or lignite, but the $\mathrm{CO}_{2}$ emissions are still high. 


\subsubsection{Steam-Methane Reforming}

Steam-methane reforming is the most commonly used technology for hydrogen production today. High-temperature steam $\left(700^{\circ} \mathrm{C}-1000^{\circ} \mathrm{C}\right)$ is used to produce hydrogen from a methane source, such as natural gas. Methane reacts with steam under 3-25 bar pressure in the presence of a catalyst to produce hydrogen, carbon monoxide, and a relatively small amount of carbon dioxide. The reaction is endothermic, and heat must be applied to the process for the reaction to proceed. Similarly to the process for brown hydrogen, the water-gas shift reaction is used to produce carbon dioxide and more hydrogen. Hydrogen is separated from carbon dioxide and the impurities in a final process step called "pressure swing adsorption" [5].

Steam-methane reforming reaction:

$$
\mathrm{CH}_{4}+\mathrm{H}_{2} \mathrm{O} \text { (+heat) } \rightarrow \mathrm{CO}+3 \mathrm{H}_{2}
$$

Water-gas shift reaction:

$$
\mathrm{CO}+\mathrm{H}_{2} \mathrm{O} \rightarrow \mathrm{CO}_{2}+\mathrm{H}_{2} \text { (+small amount of heat) }
$$

\subsubsection{Partial Oxidation}

In a process called partial oxidation, methane and other hydrocarbons are partially oxidized with pure oxygen or air to form primarily carbon monoxide and hydrogen but also nitrogen if air is used as oxidant. Partial oxidation is an exothermic process that gives off heat. The process is typically much faster than steam reforming and requires a smaller reactor vessel. Additionally, in the partial oxidation process, the water-gas shift reaction is used so that carbon monoxide reacts with water to form carbon dioxide and more hydrogen. A comparison of the chemical reactions for partial oxidation and steam-methane reforming shows that $25 \%$ less hydrogen is produced per amount of methane consumed in the partial oxidation process. However, the external energy input needed for the steam methane reforming process normally comes from combustion of the methane source increasing the actual consumption [5].

Partial oxidation of methane reaction:

$$
\mathrm{CH}_{4}+\frac{1}{2} \mathrm{O}_{2} \rightarrow \mathrm{CO}+2 \mathrm{H}_{2} \text { (+heat) }
$$

Water-gas shift reaction:

$$
\mathrm{CO}+\mathrm{H}_{2} \mathrm{O} \rightarrow \mathrm{CO}_{2}+\mathrm{H}_{2} \text { (+small amount of heat) }
$$

\subsection{Blue Hydrogen}

Blue hydrogen is obtained when $\mathrm{CO}_{2}$ that is released during the production of brown or gray hydrogen is combined with CCS technology, where the $\mathrm{CO}_{2}$ is captured and stored. This is achieved using various chemical processes. Chemicals are first used to absorb and bind the $\mathrm{CO}_{2}$. Then, the $\mathrm{CO}_{2}$ is separated from the chemicals with heat to obtain pure $\mathrm{CO}_{2}$ that is transported and stored safely under the earth's surface. The chemicals are recycled to be reused for $\mathrm{CO}_{2}$ capture. The process of separating the $\mathrm{CO}_{2}$ from the chemicals requires energy and is costly. The CCS technology is under development and is still not commercialized [6].

\subsection{Green Hydrogen}

Green hydrogen is obtained from electrolysis of water with zero greenhouse gas emissions when the electricity is produced from low-carbon sources. During electrolysis water is split by electricity into hydrogen and oxygen. The reaction takes place in electrolyzers that can range in size from small-scale equipment to large-scale central production facilities. The technology is well-suited for small-scale hydrogen production and distribution. It can also be tied directly to renewable electricity production such as wind power and solar 
power with large production variations and problems at times to deliver the power directly to the grid. The production of hydrogen by electrolysis is carried out by commercial technology that has been available for a long time but is still under further development [7].

\subsection{Turquoise Hydrogen}

Turquoise hydrogen is produced by splitting hydrocarbons. This can be achieved through different processes. The plasma process for the production of carbon black and hydrogen is probably the method that has come the furthest in development and is close to achieving commercialization. Other methods include molten metal pyrolysis by thermal splitting, catalytic conversion of methane and cold plasma. For all these processes hydrocarbons-like natural gas is used as feedstock and process energy, which comes from electricity. A total of $38 \mathrm{~kJ} / \mathrm{mol} \mathrm{H}_{2}$ is theoretically needed for splitting methane, while $285 \mathrm{~kJ} / \mathrm{mol} \mathrm{H}$ is needed for water electrolysis and $252 \mathrm{~kJ} / \mathrm{mol} \mathrm{H}_{2}$ for steam-methane reforming. High temperatures resulting in heat losses are needed for methane splitting. Overall, heat efficiency depends on factors such as process unit scale, process temperature level, heat efficiency of the electric energy input and process heat recoveries, which all vary for different methane-splitting processes. Compared with water electrolysis, methane splitting still requires 4 to 5 times less electricity than electrolysis [2].

Thermal Plasma Pyrolysis of Hydrocarbons

In 2013, Monolith Materials (Boxer Industries Inc at that time) purchased the rights to the thermal plasma process technology for synthesizing carbon black and hydrogen, which was developed by Kvaerner and SINTEF. Personnel that had been involved in the development of the process from SINTEF and Kvaerner took part in the transfer of knowledge and were partly involved in the further development of the technology. Mines Paris Tech, located in Sophia-Antipolis, France, had been working on a slightly different three-phase thermal plasma process for the production of carbon black, and hydrogen was also involved in the development work.

In 2014-2015 Monolith's Seaport 2 MW pilot demonstration plant was built in Redwood City, California, and started producing carbon black and hydrogen in 2015. Over the next three years, the company ran the plant to determine product range and reliability, demonstrate yield and stockpile samples for further testing [8].

Monolith started building a one-unit industrial plant in Hallam, Nebraska, in October 2016. The planned production capacity is $14,000 \mathrm{t} / \mathrm{y}$ carbon black and $4200 \mathrm{t} / \mathrm{y}$ hydrogen. By the end of 2020, the plant was in the late stages of commissioning. Run lengths were typically around $200 \mathrm{~h}$ and increasing. According to Pete Johnsen, the cofounder of Monolith Materials, the plasma torch operates at power $>10 \mathrm{MW}$ and runs very stably in environments with $>90 \% \mathrm{H}_{2}$ as well as lower $\mathrm{H}_{2}$. The plasma torch is based loosely on the SINTEF/Kvaerner torch concept but with a number of modifications and improvements, as it has been scaled up. The thermal efficiency of plasma torch is $>95 \%$. The produced carbon black matches commercial specifications, and they do not have any fouling issues in the reactor. In the next step they are planning to build 12 more units, increasing the capacity to $194,000 \mathrm{t} / \mathrm{y}$ carbon black. According to Monolith, it will be the largest carbon black manufacturing facility in the US. Construction is set to begin in Q2 2021 with completion in 2024 [9].

The original plan was to return produced hydrogen to the local electric power plant, but they are now planning to build a 275,000 $\mathrm{t} / \mathrm{y}$ carbon-free anhydrous ammonia plant in Hallam, Nebraska, to process hydrogen. The ammonia product is intended for use in the local fertilizer market. KBR will provide a technology license, basic engineering design package, proprietary equipment and catalyst for a 930 metric tons per day ammonia synloop plant [10].

After expanding the facility in Nebraska to include 12 more reactors that are replicas of the currently operating reactor, the commercial plan is then to build subsequent plants in other locations in the US before expanding into Europe and Asia, potentially with a version 
of the furnace that produces other types of carbon. At Monolith they are still focused on Carbon Black for now but have some early R\&D going into other types of carbon, generally aiming for low-value large market products [9].

Though the numbers are a bit higher because of carbon black process modifications, in the long term, Monolith expects the process to use about $210 \mathrm{MMBtu}\left(5935 \mathrm{Nm}^{3}\right)$ of natural gas and 12-15 MWh of electricity to produce 1 ton of $\mathrm{H}_{2}$. They see this as being far more competitive for low-carbon $\mathrm{H}_{2}$ than electrolysis, and Monolith are seeing strong interest from industrial customers because of that. From a capex standpoint, the typical cost of SMR (steam-methane reformation) is about USD 3000/tpy, and the cost of electrolysis is likely trending towards USD 4000/tpy (assuming high-capacity factor). It is expected that an optimized pyrolysis system will end up between USD 4000-5000/tpy $\mathrm{H}_{2}$ but have significant operating cost advantages over electrolyzers. The other relevant bit of information for comparison is that Monolith does not believe it makes sense to build small pyrolysis plants. They believe a minimum commercial scale will likely be around 25,000 tpy $\mathrm{H}_{2}$. That is a disadvantage compared to the modularity of electrolyzers [9].

$\mathrm{CO}_{2}$ emissions for the Monolith process depend on the $\mathrm{CO}_{2}$ footprint of the power used and the greenhouse effect of methane leakage converted to $\mathrm{CO}_{2}$ e. $0.67 \mathrm{TCO}_{2} \mathrm{e} / \mathrm{TH}_{2}$ is given for electricity from pure renewables. It is possible to make this a negative number by using a portion of landfill gas or biomethane. In the plant in Nebraska, Monolith will mix in enough landfill gas to make the net $\mathrm{CO}_{2}$ output 0 , which is equivalent to renewable electrolysis [11].

Nils Myklebust, who has participated in the process development for both Kvaerner and Monolith, believes that the process operating temperature can be lowered, thereby reducing the energy demand for the process if the aim is not to produce high-quality carbon black but hydrogen and lower qualities of carbon [12].

\subsection{Consumption Data and $\mathrm{CO}_{2}$ Emissions for Hydrogen Production Methods}

The natural gas consumption, oxygen consumption/production, carbon black production, electric energy consumption and $\mathrm{CO}_{2}$ emissions per ton of hydrogen produced for some different hydrogen production methods are listed in Table $1 . \mathrm{CO}_{2}$ emissions and energy consumption connected to the production of raw materials and electricity are not included. $\mathrm{H}_{2} \mathrm{O}$ consumption, which is important at some locations, is not included. The given values must be regarded as approximate net values based on present technology or suggested technology based on present knowledge. The values for blue hydrogen with steam-methane reforming and auto thermal reforming with carbon capture and storage were calculated from figures given in examples of the process simulations.

Table 1. Natural gas consumption, oxygen consumption/production, carbon black production, electric energy consumption and $\mathrm{CO}_{2}$ emissions per ton hydrogen for different production methods.

\begin{tabular}{|c|c|c|c|c|c|}
\hline Production Method & $\begin{array}{l}\text { Natural Gas Cons. } \\
\qquad\left[\mathrm{Nm}^{3} / \mathrm{T} \mathrm{H}_{2}\right]\end{array}$ & $\begin{array}{c}\text { Oxygen } \\
\text { Cons./Prod. } \\
{\left[\mathrm{Nm}^{3} / \mathrm{T} \mathrm{H}_{2}\right]}\end{array}$ & $\begin{array}{c}\text { Carbon } \\
\text { Production } \\
{\left[\mathrm{T} \mathrm{CB} / \mathrm{T} \mathrm{H}_{2}\right]}\end{array}$ & $\begin{array}{c}\text { Electric Energy } \\
\left.\text { Cons. [MWh/T H } \mathrm{H}_{2}\right]\end{array}$ & $\begin{array}{c}\mathrm{CO}_{2} \text { Emissions } \\
{\left[\mathrm{T} \mathrm{CO}_{2} / \mathrm{T} \mathrm{H}_{2}\right]}\end{array}$ \\
\hline Gray (SMR) ${ }^{4}$ & $4585-5604$ & 0 & 0 & 0 & $9-11$ \\
\hline Blue (SMR with CCS) ${ }^{3}$ & $4600-5000$ & 0 & 0 & 0 & 0.8 \\
\hline Blue (ATR with CCS) ${ }^{3}$ & 4000 & 2300 cons. & 0 & 1.2 & 0.43 \\
\hline Green (electrolyses) $^{2}$ & 0 & 5561 prod. & 0 & $50-55$ & 0 \\
\hline Turquoise (Monolith) $^{1}$ & 5935 & 0 & 3.33 & $12-15$ & 0.67 \\
\hline
\end{tabular}

${ }^{1}[9] ;{ }^{2}[13] ;{ }^{3}[14] ;{ }^{4}[15]$.

\section{Valorization of by-Products}

The profitability of turquoise hydrogen processes is very dependent on the obtainable prices for the carbon products and also the local availability and prices of electricity and natural gas. If the process is run with biomethane produced by anaerobic digestion of organic waste, the hydrogen and carbon produced can be considered $\mathrm{CO}_{2}$-free as long 
as the electric energy input comes from low-carbon energy sources. It seems possible to develop a process for the $\mathrm{CO}_{2}$-free production of both hydrogen and carbon reductants that the metallurgical industry needs in the future

Green hydrogen from electrolysis gives oxygen as by-product, which might be used for industrial applications, but the demand for oxygen is almost certainly limited compared with the need for $\mathrm{CO}_{2}$-free hydrogen. Fish farms for breeding fry are among the potential users of oxygen and surplus heat from water electrolysis.

\section{Conclusions}

The production of hydrogen with a low-carbon footprint is possible, but competing green, blue and turquoise alternatives are all dependent on electric energy input from low-carbon energy sources to produce a noticeable reduction in $\mathrm{CO}_{2}$ emissions. In the coming decades, the global availability of electricity from low-carbon sources will be limited. The need for hydrogen will increase, and production methods that require lower electric energy input and at the same time have low $\mathrm{CO}_{2}$ emissions such as turquoise and blue hydrogen should therefore be generally preferred and used before the green alternatives that require a much higher electric energy input.

The monolith thermal plasma process for the production of carbon black and hydrogen a further development of the process developed by Kvaerner and SINTEF is the only turquoise or blue hydrogen production process that has reached industrialization. Compared with the other turquoise alternatives, thermal plasma pyrolysis operates at the highest temperature and needs, in principle, the highest electric energy input. However, the heat efficiency can be high, and heat can be recovered from hot products. There is a potential for lowering the temperature in thermal plasma processes if hydrogen production is given priority above the quality of the carbon black product. The other turquoise alternatives are also performed at elevated temperatures. It is doubtful whether non-thermal plasma, catalytic pyrolysis or liquid metal/salt pyrolysis can provide significantly lower electric energy consumption than the thermal plasma processes. The electric energy consumption and total $\mathrm{CO}_{2}$ emissions for quite complex blue alternatives also looks uncertain.

The profitability of turquoise hydrogen processes is very dependent on the obtainable prices for the carbon products and the local availability and prices of electricity and natural gas. If the process is run with biomethane produced by the anaerobic digestion of organic waste, hydrogen and carbon produced can be considered $\mathrm{CO}_{2}$-free if the electric energy input comes from low-carbon energy sources. It seems possible to develop a process for the $\mathrm{CO}_{2}$-free production of both the hydrogen and carbon reductants needed by the future metallurgical industry.

Funding: This publication was funded by the SFI Metal Production (Centre for Research-based Innovation, contract No. 237738). The authors gratefully acknowledge the financial support from the Research Council of Norway and the partners of the SFI Metal Production.

\section{References}

1. Bakken, J.A.; Jensen, R.; Monsen, B.; Raaness, O.; Wærnes, A.N. Thermal plasma process development in Norway. Pure Appl. Chem. 1998, 70, 1223-1228. [CrossRef]

2. Philibert, C. Methane Splitting and Turquoise Ammonia. Available online: https://www.ammoniaenergy.org/articles/methanesplitting-and-turquoise-ammonia/ (accessed on 14 December 2020).

3. Innovations for a Climate-Friendly Chemical Production. Available online: https://www.basf.com/no/en/who-we-are/ sustainability/we-produce-safely-and-efficiently/energy-and-climate-protection/carbon-management/innovations-for-aclimate-friendly-chemical-production.html (accessed on 23 December 2020).

4. About Hazer Group. Available online: https://hazergroup.com.au/about/\#hazerprocess (accessed on 23 December 2020).

5. Hydrogen Production: Natural Gas Reforming. Available online: https://www.energy.gov/eere/fuelcells/hydrogen-productionnatural-gas-reforming (accessed on 15 December 2020).

6. Benjaminsen, C. This Is What You Need to Know about CCS-Carbon Capture and Storage. Available online: https://www.sintef no/en/latest-news/this-is-what-you-need-to-know-about-ccs-carbon-capture-and-storage/ (accessed on 19 December 2020).

7. Hydrogen Production: Electrolysis. Available online: https://www.energy.gov/eere/fuelcells/hydrogen-production-electrolysis (accessed on 14 December 2020). 
8. The Monolith Story. Available online: https://monolithmaterials.com/about/our-story (accessed on 22 December 2020).

9. Johnson, P. Azimuth Capital Management. Personal communication, 3 December 2020.

10. KBR's Energy Efficient Ammonia Technology Selected by Monolith Materials for New Process with Zero $\mathrm{CO}_{2}$ Emissions. Available online: https:/ / www.kbr.com/en/insights-events/press-release/kbrs-energy-efficient-ammonia-technology-selectedmonolith-materials (accessed on 22 December 2020).

11. Johnson, P. Azimuth Capital Management. Personal communication, 28 May 2021.

12. Myklebust, N. NM Teknokonsult AS. Personal communication, 7 December 2020.

13. Electrolysis of Wate. Available online: https:/ / en.wikipedia.org/wiki/Electrolysis_of_wate (accessed on 9 March 2021).

14. Sadler, D.; Anderson, H.S. H21 North of England, Report. Available online: https:/ /web.achive.org/web/20201101013819-/https: //www.h21.green/wp-content/uploads/2019/01/H21-NoE-PRINT-PDF-FINAL-1.pdf (accessed on 26 March 2021).

15. Muradov, N. Low-carbon production of hydrogen from fossil fuels. In Compendium of Hydrogen Energy; Subramani, V., Ed.; Woodhead Publishing: Orlando, FL, USA, 2015; pp. 489-522. 